\title{
Biotech value chain and technologies for COVID-19 research areas for collaboration on cost quality tradeoff with tool companies
}

\author{
Christine C. Huttin ${ }^{\mathrm{a}, \mathrm{b}}$ \\ ${ }^{\mathrm{a}}$ Business and Economics of HealthCare, University Aix Marseille, Marseille, France \\ ${ }^{\mathrm{b}}$ CEO, Endepusresearch, Inc., Cambridge, MA, USA \\ E-mails: christine.huttin@iae-aix.com and chxyinfo@endepusresearchinc.com
}

Received 19 August 2021

Accepted 3 November 2021

\begin{abstract}
.
BACKGROUND: Technologies for COVID-19 are in high demand, and supply chains from biotech and pharma industries face critical supply issues.

OBJECTIVE: This paper discusses the case on mRNA technologies and quality assurance issues.

METHODS: Interviews with managers of biotech companies were performed. These helped to prepare biotech panels at a roundtable on quality of medicine, organized by the Polish Academy of Sciences in Paris (PAN) in 2021.

RESULTS: This paper analyzes the new mRNA technology and shows the importance of emerging new biotech firms, especially tool companies providing services in quality assurance. It highlights research areas and types of survey instruments with academic collaborators, to better understand the economics of mRNA technology platforms.

CONCLUSIONS: A future research agenda for collaboration with academic communities is proposed on cost-quality tradeoffs and clinical quality attributes for such genomic technologies.
\end{abstract}

Keywords: Biotech value chain, tool companies, mRNA technology, cost and quality, COVID-19, healthcare

\section{Introduction}

This paper is written following an event organized by the Polish Academy of Sciences in Paris on quality in medicine. Since the COVID-19 crisis has led to revisions of most health policies, this paper discusses some issues related to successful technology strategies to tackle the global pandemic and costquality tradeoffs for scaling up such technologies and different forms of technology transfer (licensing, alliances or partnerships). This involves major companies and international organizations (World Trade Organization (WTO), World Health Organization (WHO), Organisation for Economic Cooperation and Development (OECD)) on main areas of conflicts: trade and patent/IP versus public health (access to vaccines and treatments, affordability). 


\subsection{The concept of value chain $(G V C)$ and biotech research and development}

The concept of value chain was first used in a paper to analyze the diffusion of ICT in the global pharmaceutical industry [1], facing a fast digitalization and interconnectivity of flows of products and services. The international dataset called Trade in Added Value $(\mathrm{TiVa})^{1}$ was created under an initiative of Singapore and OECD for trade policies. It was then extracted for input and output on all sectors from chemicals and ICT, which are useful to measure international flows of trade and domestic demand for pharmaceuticals and chemicals.

In this second paper, the conceptual approach is also used as a representation of research and development steps in a biotech development chain; it helps to position the roles of various tool companies as service providers to main pharmaceutical companies for the supply of innovative life science technologies. The selected technologies are relevant to produce COVID-19 vaccines: mRNA technologies.

\subsection{The case study on genomic technologies used to develop vaccines and viral strategies in the fight against COVID-19}

The main reason to use a value chain approach in this paper is to identify cases of service companies supporting pharma companies in the development of their vaccines. This also identifies critical quality or cost issues, which could benefit from additional quality instruments. Since the discovery of the DNA model by Watson and Crick in 1953, genomic research has been a very fast scientific-driven field; it has enhanced the diagnostic space especially with genetic sequencing technologies used for predicting diseases by incorporating polygenic risk scores and eliminating genetic mutations. Gene editing and CRISPR research then led to gene editing allowing for the development of DNA sequencing technologies. Finally, the current stage of genomic research had led to the production of proteins with modifications of cells ("virus into cell"). The production of viral proteins led to new types of vaccines that are especially successful in fighting COVID-19 with RNA therapies.

RNA is a molecule between DNA and protein, which helps to access information on "what is going on in cells", using tools that have been developed for DNA [4]. The name of tool companies is then given to the biotech companies involved in such tools. It is timely then to understand the mRNA technology platforms and how biotech tool companies can help analyze these technologies.

\subsection{Tool companies in RNA technologies in the biotech global development chain}

RNA is a versatile molecule; to use it for therapies, especially drugs or vaccines, some form of stabilization is required. Firms must demonstrate to regulators what is called High Order Structure (HOS) studies, which can provide sufficient evidence that RNA structures are stable. In addition, the RNA structure is considered large and thick and therefore requires encapsulation, for instance with nanoparticles. Advances in cancer research with the new anticancer drugs called immunotherapies have helped accelerate the research and production of mRNA technologies, especially for their use as COVID-19 vaccines.

However, as all R\&D in genomics, mRNA technologies for COVID-19 face issues of scaling up in development stages and possible diseconomies of scales. Development stages where biotech tool

\footnotetext{
${ }^{1}$ For additional information on such measures on international flows of productions and services or flows of upstream and downstream tasks generations [2], see OECD-WTO, TiVa project [3].
} 
Table 1

Collaboration on cost quality tradeoffs: identification of cost drivers and impact on R\&D productivity in the lead stages of the biotech value chain

\begin{tabular}{ll}
\hline Research areas for collaboration between & Examples of impacts of cost drivers: \\
academics and tool companies & - Lead time increases and reduces productivity of R\&D \\
& - Automation reduces costs and increases productivity \\
& - Additional ad hoc studies increase the cost of scaling up \\
& - Costs vary with complexity, e.g. how do structure interactions between sec- \\
& ondary, tertiary and quaternary evolve? \\
\hline
\end{tabular}

Source: Professor Huttin, June $16^{\text {th }} 2021$, PAN conference.

Table 2

Collaboration on cost quality tradeoffs: identification of critical quality attributes in the lead stages of the biotech value chain Research areas for collaboration between On quality: need to identify the critical quality attributes to reach safety and academics and tool companies efficacy for regulators and end users. Examples of interactions of proteins:

- Which criteria to use: aggregation, stability?

- Issues with: assurance laboratory costs, scaling up cost

Source: Professor Huttin, June $16^{\text {th }} 2021$, PAN conference.

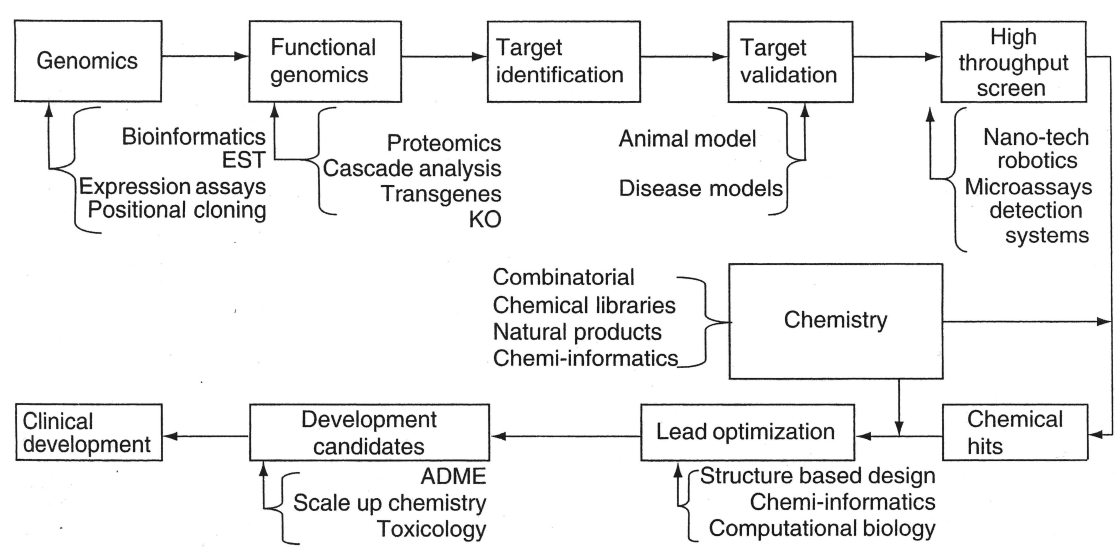

Fig. 1. The "omics" development chain [5].

companies can help with quality assurance, can be identified in Fig. 1, which describes the biotech development chain: these types of service companies mainly interact at the lead optimization stage and for the development of candidates (scaling up of the required chemistry and toxicology).

A cooperation with the academic research community can help identify cost drivers, their impact on R\&D productivity in lead stages of the biotech value chain and potential tradeoffs with quality. For mRNA technologies, the Critical Quality Attributes (CQAs) especially deal with interactions of proteins and the selection of criteria to ensure stability. HOS studies, necessary for regulatory approval, in such cases are more complex because of the molecule characteristics. More ad hoc studies are needed at the scale up stage, which increases the development costs. Tables 1 and 2 highlight some of the research areas on cost quality tradeoffs and quality attributes to facilitate a fast development of mRNA therapies, especially for COVID-19 vaccines. 


\section{Conclusions}

The biotech panel of the conference on quality of medicine at the Polish Academy of Science in June 2021 in Paris was useful to propose a research agenda that would enhance the development of critical mRNA technologies used for COVID-19 and possibly cancer vaccines. Current datasets such as TiVa from OECD/WTO used for trade and pharmaceutical policies do not seem to provide sufficient statistical information to measure the critical steps on the biotech development chain. ${ }^{2}$ One of the contributions of this paper is to propose new survey instruments that would involve the collaboration of lab directors for quality assurance and scale up. This would generate data for cost analysis and quality management.

\section{Acknowledgments}

Professor Christine Huttin is thankful to the Polish Academy of Science for the invitation and to Dr Margaret Chalupowski for her role in the organization of the conference on Quality of Medicine in Paris (France). She is also grateful to Professor R Smith for his review of this paper and P O'Callaghan for editing the last version of the paper.

\section{Conflict of interest}

None to report.

\section{References}

[1] Huttin CC, Global value chains and international pharmaceutical policy. Technology and Health Care, 28 (2020), $337-344$.

[2] Antras P, Chor D, Organizing the Global Value Chain, Econometrica, Vol. 81, N 6 Nov 2013, 2127-2204.

[3] OECD-WTO Project to measure Trade in Value Added (TiVa), June 2015. http://www.oecd.org/trade/value added.

[4] Messina D, "RNA is a powerful, versatile molecule" Advanced Applications, Cofactor Genomics, Molecular Diagnostics, January 31st, 2019.

[5] Sammut SM, Biotechnology business and revenue models. Chapter 4. In: The Business of Healthcare Innovation. Ed: LR Burns. Cambridge University Press, 2005.

\footnotetext{
${ }^{2}$ Disaggregated nomenclatures are required to help industrial policies in the field of pharmaceuticals and life science. An updated version of the TiVa database or BERD database from OECD could be useful. Alternatively, consulting firms such as McKinsey run in-house surveys helping international companies to measure the added value of different elements in the development chain.
} 